\title{
Do 'Robin Hood às avessas' ao artista-flâneur: por um teatro imanente nas cidades
}

Altemar Di Monteiro*

\begin{abstract}
RESUMO: Frente à ruptura epistemológica com os conceitos de sujeito e mundo como unidades isoladas é possível pensar na noção de um artista-cidadão que se apropria do espaço público para a produção de diálogos com o teatro imanente nas ruas das cidades. A ideia de uma cidade-arte surge como resistência à cidade-marketing e o papel do artista inserido nesse tensionamento passa a exigir uma percepção aguçada das forças dinâmicas desse contexto para a configuração do 'exercício experimental da liberdade'. Pensando nas criações estéticas produzidas nas periferias e atento às ideias de Hélio Oiticica, Enrico Rocha e Amir Haddad, defendo aqui um artista-flâneur, aquele que, observando os espaços, percebe a sua implicação direta na produção de um mundo-arte e de uma arte pública.
\end{abstract}

PALAVRAS-CHAVES: artista-cidadão; flâneur; arte pública.

ABSTRACT: In opposite to epistemological break with the concepts of subject and world as isolated units it's possible to think of the notion of an artist-citizen that appropriates the public space for the production of dialogues with the theater immanent in the city streets. The idea of a city-art comes as resistance to a citymarketing and the role of the artist on this tension comes to require an keen awareness of the dynamic forces on this context to configure the 'experimental exercise of freedom'. Thinking on the aesthetic creations produced in the peripheries and attentive to ideas of Hélio Oiticica, Enrico Rocha and Amir Haddad, I defend here the idea of an artist-flâneur, that one who, looking the spaces, feels its direct implication in the production of a world-art and a public art.

KEYWORDS: artist-citizen; flâneur; public art.

Fortaleza - CE, julho de 2015.

\footnotetext{
*Altemar Di Monteiro é ator e diretor teatral do Grupo Nóis de Teatro. Tecnólogo em Artes Cênicas, Licenciado em Teatro e Especialista em Arte Educação. Mestrando em Arte Contemporânea pela UFC e Bolsista FUNCAP.
} 
"Pensar o espaço, o local dos espetáculos e, associado a isto, pensar a dramaturgia, o ator e as suas relações com o espectador, é também pensar o mundo." (HADDAD, 2008, p. 149).

\section{Artista-cidadão: um exercício experimental da liberdade}

Foi-se o tempo em que as sociedades burguesas estruturaram um sistema-mundo que separa arte e vida, artista e público, investindo num "endeusamento" da arte e colocando-a num pedestal de difícil alcance sensorial, cognitivo e de atravessamento. O universo simbólico de um contingente de expressões contemporâneas, em revanche, tem construído uma pertinente reivindicação de retorno ${ }^{1}$ às bases de contato entre o que é arte e o que é público, entendendo este último para além da noção de "plateia", mas incorporando nesse panorama a ideia de uma "cultura comum" 2, da troca existente no pensamento de uma "comunidade" em diálogo e construção pública e política.

O conceito de público passa a ser expandido para uma compreensão de que a pólis é construtora de saber poético e engenha uma série de significados simbólicos imanentes na sua experiência cotidiana, trazendo a tona o papel do artista como catalisador desse espírito para a expressão de um mundo-arte passível de ser revisto no campo do sensível. Quando Hélio Oiticica diz que "o museu é o mundo" traz consigo uma perspectiva revolucionária de entendimento do universo fenomenológico da vida cotidiana enquanto dispositivo poético, ampliando seu olhar sobre o mundo, entendendo-se como parte integrante dele, implicado na sua construção, derrubando assim as barreiras que separam arte e vida. É nessa via que os espaços oficiais da arte, sejam museus, galerias e teatros passam a ser transgredidos da sua disposição privativa, suscitando esse desejo de rua tão latente nas discussões sobre arte na contemporaneidade. Parte-se, então, da compreensão da cidade como grande teatro poético que, em si, possui um arcabouço de significados a ser explorado, tendo os sujeitos como protagonistas dessa construção, no seu manuseio dos significados, no constante trânsito da urbanidade e, mais ainda, nos conflitos e tensionamentos capazes de revelar o drama estabelecido no curso da noção de História e de Cultura.

É nesse contexto que uma grande leva de artistas tem se interessado em pensar a urbes como latência criativa, dialogando com seus espaços topográficos, arquitetônicos, simbólicos, econômicos e culturais. A noção de cultura passa, então, a ser ampliada na sua dicotomia 
com a natureza, para pensar numa cultura-natureza que se transforma e é transformada mutuamente, reparando essa distancia entre artista-cidadão e mundo ${ }^{3}$, arte e vida, visto que "os meios culturais que usamos para transformar a natureza são eles próprios derivados dela" (EAGLETON, 2011, p. 11). A partir dessa compreensão, em referência a Hélio Oiticica, o artista cearense Enrico Rocha" traz a noção tão pertinente de que "o mundo é a obra". Obra entendida não somente enquanto produto, mas como esse fazer constante da criação artística, obra como processo, colocar a "mão na massa", anúncio já preconizado por Merleau-Ponty (1992, p. 138) quando se perguntava: "Onde estamos, onde nos posicionamos, para estabelecer um limite entre o corpo e o mundo já que o mundo é carne "? Assim, pensar no mundo enquanto obra implica entender que ele não está posto como tal, mas que é construído por uma série de atuações realizadas nele e junto com ele. "Se somos seres culturais, também somos parte da natureza que trabalhamos. Com efeito, faz parte do que caracteriza a palavra 'natureza' o lembrar-nos da continuidade entre nós mesmos e nosso ambiente" (EAGLETON, 2011, p. 11). O mundo passa, então, a ser o quadro do pintor, o palco do ator, o instrumento do músico, a matéria-prima do artista que sai do seu isolamento intuitivo para perceber que nas relações cotidianas da cidade surge de forma imanente, outro poético emergente de ser visto vivido e experimentado pela comunidade que o constrói. "Nesse sentido não somos do mundo, mas somos o mundo. Então partimos da vida, ou partimos a vida, e a inventamos. E por ser a vida uma invenção de sentidos, ela é estética" (ROCHA, 2014).

O papel do artista-cidadão inserido nesse novo argumento estaria, desse modo, na capacidade desvendar na vida cotidiana das cidades a sua poética, propondo práticas mobilizadoras desse cidadão-artista à transformação cotidiana das suas realidades como lugar sensível, na busca da ruptura com o homem-máquina do mundo contemporâneo. O artista lança mão de ser um mero criador de objetos, compreendendo-se também como objeto desse mundo-obra, abrindo-se ao sensível inscrito na poética dos espaços e arquiteturas públicas. Desse modo, a diferença entre a cidade-máquina e a cidade-arte estaria no modo como se opera a experiência com o sensível, no trato com a linguagem e na reviravolta de uma visão de um mundo cotidiano posto, aquele impossível de transformação. Oiticica, importante artista na construção dessa compreensão, refere-se muitas vezes a uma "repulsa pelo cotidiano", ampliando a experiência do dia-a-dia para uma invenção do mundo, capaz de ser transformado pela singularidade do viver autêntico. Quando a cidade-máquina passa a compreender seu 
cotidiano como lugar sensível, a arte deixa de habitar esse espaço endeusado para a potencialização do saber imanente na vida do sujeito, que deixa de ser espectador passivo de uma experiência para ser coautor, ou no dizer de Rancière: um espectador emancipado.

"A lição emancipadora do artista, oposta termo a termo à lição embrutecedora do professor é a de que cada um de nós é artista, na medida em que adota dois procedimentos: não se contentar em ser homem de um ofício, mas pretender fazer de todo trabalho um meio de expressão; não se contentar em sentir, mas buscar partilhá-lo". (RANCIÈRE, 2002, p. 79)

Do mesmo modo que Oiticica, uma série de outros artistas trabalhou para a construção de uma poética de diálogo imanente com a cidade, a sociedade e suas culturas, contribuindo para a compreensão do termo, em voga desde os anos de 1970, de uma arte pública ${ }^{6}$. Esta noção aqui reivindicada amplia a compreensão do acesso aos produtos de arte nos espaços públicos (em sua maioria monumentos), para repensar a forma como o espectador se relaciona com o mesmo, tirando-o do lugar de contemplação para a noção de experiência a ser vivida. Nesse contexto, as artes cênicas muito têm contribuído para essa reflexão, seja nas suas intervenções urbanas ou mesmo nas performances e happenings realizados nos espaços públicos das cidades desde os anos 1970. No Rio de Janeiro, o Grupo Tá na Rua, existente desde 1980, tem construído uma fundamental reflexão sobre as questões aqui citadas, trazendo para o teatro a potência desse encontro com a cidade estabelecendo o seu discurso poético junto a ela, nesse espaço de troca e apropriação com o espaço público, revelando sua imanência poética e buscando "pensar toda a cidade como uma possibilidade teatral - ela é o espaço de representação, suas ruas e edifícios são a cenografia e os atores são os cidadãos" (HADDAD, 2008, p. 219).

Essa restauração da comunhão do artista com a cidade pode ser visto como chave importante para repensar a função da arte no contexto das cidades, onde, nas palavras de Amir Haddad, diretor do grupo Tá na Rua (2008, p. 224), "tudo é público e nada é especializado. O cidadão e o artista são as mesmas pessoas e as representações teatrais se transformam em acontecimentos públicos". Guatarri e Rolnik (1986, p. 22), contribuindo nesse debate e apresentando a noção de cultura como um conceito reacionário, ao contrário de Haddad, reivindicam o valor especializado da cultura, investindo numa compreensão das singularidades em contraponto à hegemonia dos discursos capitalísticos ${ }^{7}$, perguntando-se, porém, 
"Como fazer com que essas categorias ditas "da cultura" possam ser ao mesmo tempo, altamente especializadas, singularizadas (...), sem que haja por isso uma espécie de posse hegemônica pelas elites capitalísticas? (...) Como proclamar um direito à singularidade no campo de todos esses níveis de produção, dita "cultural", sem que essa singularidade seja confinada num novo tipo de etnia?".

Pensar a arte como um acontecimento público, uma "cultura comum", significa ampliar o seu alcance simbólico dentro do mundo contemporâneo e, nesse sentido, o próprio Grupo Tá na Rua, mesmo discordando da especialização do conhecimento, apropria-se na noção de arte pública, inserindo também a noção da arte enquanto direito civil, onde assim como à saúde e à educação pública, o cidadão tem o direito a uma arte pública, financiada com recurso público como interesse geral da nação. Assim, ao modo que a cidade-máquina se compreenda como cidade-arte, o sujeito passa a se relacionar com a arte-ofício (aquela realizada de modo especializado pelos artistas que a tem como profissão) de modo emancipado, momento em que ele pratica, conforme Amir Haddad (2008, p. 225), "o exercício dessa ludicidade e assume um único papel - o de ser humano livre, criativo, fértil, transformador", caminhando para a experiência aprofundada com o universo de códigos do mundo e tendo a arte como "exercício experimental da liberdade" e a sua própria vida como arte.

Não querendo entrar na celeuma teórica da noção de liberdade, mas a colocação de Mário Pedrosa (1970, p. 308) no texto "Por dentro e por fora das Bienais" de 1970 faz-se útil:

\footnotetext{
“Daí surgiram, ao lado de produções ainda manipuladas e manipuláveis pelo mercado de arte, as mais desabridas ou as mais nilistas experiências atuais, por aqui e pelo mundo. Eles se entregam, consciente ou inconscientemente, a uma operação inteiramente inédita com esse caráter extrovertido de massa nas sociedades burguesas ou nas sociedades em geral: o exercício, mas o exercício experimental da liberdade. E a primeira consequência disto é não criar para o mercado capitalista, é não criar para que tudo de novo se metamorfoseie em valor de troca, isto é, em mercadoria. (...). É possível que muitos desses artistas sonhem ou já se inspirem numa aspiração utópica (...) de uma sociedade em que o homem não trabalhe mais para ganhar a vida com o suor de seu rosto, para que pelo trabalho e pelo lazer, sem mais diferenças entre um e outro, aprenda a viver."
}

A compreensão de Mário Pedrosa sobre esse exercício experimental (embora utópico) da liberdade é a defesa de uma arte cada vez mais perto da vida, diminuído distâncias que não 
necessariamente trazem a arte para perto do valor econômico da vida e das culturas de massa, generalizando-a num discurso hegemônico, mas que, pelo contrário, propõe práticas que trazem o espectador-máquina para a desconstrução de suas experiências e estabeleça um "estado de invenção", modo de pensar possível catalizador da experiência sensível e singular no homem contemporâneo em relações com a cidade e com as obras artísticas, ou mais ainda, com o mundo-obra.

Esse exercício experimental é alimentado pelo desejo sempre presente de transformação da história, do determinismo da natureza e do sentido teleológico da morte. O assombro com a finalidade da matéria e o cotidiano enquanto espaço de tempo dessa transição são contrapostos ao sentido poético de transformação da natureza, pensamento que é potencializado com o olhar estético sobre o mundo e o que ele pode produzir de sentido no seio da cultura. É quando os conceitos de arte e vida, cultura e natureza, se fundem numa presença intempestiva que se pode visualizar o caminho para esse exercício da liberdade, não levando "muito a sério a própria natureza, na medida em que as ficções da 'cultura' podem ser utilizadas em proveito da compaixão corporal" e não reduzindo também essa cultura ao corpo natural, "um processo do qual a morte é o símbolo derradeiro, já que isso pode levar ou a ser uma presa brutalizada dos próprios apetites ou a um materialismo cínico para o qual nada além dos sentidos é real." (EAGLETON, 2011, p. 147)

\section{Robin Hood às avessas: um novo mercado de cultura a ser capitalizado}

A investida poética revista nesse ínterim produz uma situação nova, em especial no Brasil, quando um número incontável de artistas parte rumo às periferias na estruturação de um discurso de ruptura com os espaços oficiais de produção de saber e fruição. Esse levante, embora se torne pertinente diante do contexto de segregação histórica entre centro e periferia, erudito e popular, anuncia consigo uma reviravolta no modo de pensar a produção artística das e nas periferias brasileiras. O que antes pouco era notado pelas sociedades burguesas e pela produção oficial das artes passa a ser visto como espaço de mobilização capitalística.

\footnotetext{
'Não demorou muito para que o circuito de artes - esse potente e voraz dispositivo colonizador, que hierarquiza as experiências estéticas, quando não as padroniza - absorvesse e absolvesse essas relações, mobilizando sujeitos, instituições e economias na produção de situações fundamentadas no interesse pela periferia." (ROCHA, 2014).
} 
Exemplo disto é o resultado da Lei de Fomento do Teatro em São Paulo que tem feito uma série de coletivos mobilizarem ações para a realização de suas práticas nas periferias, criando grupos novos e gerando projetos e produtos que partem desse lugar. Ao passo que as produções artísticas passam por um relevante processo de democratização territorial, a produção cultural cria um novo métier de economia da cultura, ávido por financiamento público, refletindo o paradoxo da revolução apropriada pelo mercado. Em contraponto, as criações artísticas que nascem nas próprias periferias e seu discurso poético ainda passam por um processo de reivindicação de sua singularidade poética, vista muitas vezes como uma arte menor ou deslocada dos conceitos e poéticas da contemporaneidade, o que pode significar a incompreensão do valor de contracultura vivenciado pelos lugares não oficiais na sua ruptura com o endeusamento da arte no mundo contemporâneo. Para pensar uma cidade-arte, onde territórios de produção de saber estético não precisem ser legitimados pelo poder econômico ou por relações políticas estabelecidas no circuito da arte, faz-se necessário e urgente compreender a potência poética das periferias na sua singularidade de espaço, arquitetura e produção simbólica. Enrico Rocha (2014) pergunta-nos se no atual ambiente da arte não temos agido como uma espécie de "Robin Hood às avessas", onde "em nome da arte, saímos em busca da principal - muitas vezes a única - riqueza dos pobres, sua própria existência, e a levamos para os centros de consumo estético frequentado por aqueles que já usufruem toda e qualquer riqueza produzida no mundo".

Pensar numa arte que rompe realmente com espaços de produção oficial não significaria, então, romper apenas com as estruturas arquitetônicas da realização e fruição desses bens, mas descontruir constantemente as relações de poder estabelecidas no campo da produção de arte, numa reconexão, conforme defendido outrora, entre artista e público, desmontando o valor simbólico da obra enquanto produto fechado a ser consumido e ampliando-a para a construção processual vivida no instante-já dessa conexão com o que é público. Desse modo, parece-me pertinente pensar na poética das periferias não apenas como espaço de produção a ser visitado em modelos de descentralização e democratização da arte e do discurso de produção de cultura, mas como lugar singular que suscita no seu próprio cotidiano outros modos e valores de relação com o mundo e com a cidade, transgressão constante da própria noção de Mercado e de Cultura. 
Há no Brasil uma fantasia de democratização da cultura que "não está realmente conectada com os processos de subjetivação singular, com as minorias culturais ativas - o que faz com que ela restabeleça sempre, apesar das boas intenções, uma relação privilegiada entre o Estado e os diferentes sistemas de produção cultural" (GUATARRI, ROLNIK, 1986, p. 23). O "Robin Hood às avessas" retorna trazendo o constante desafio desse artista em realmente estabelecer o diálogo com o espaço em que sua obra se inscreve para que não haja o furto dos valores simbólicos das periferias para a legitimação no discurso oficial. Faz-se necessário, pelo contrário, um artista que é contaminado pelas práticas suburbanas, entendendo-as como poéticas, e realiza um verdadeiro escambo de troca e diálogo, compreendendo-se também como sujeito implicado nesse movimento e que os resultados advindos desse encontro precisam ser uma construção da soma e não da subtração e do furto, descontruindo também a própria ideia do que é ser artista e do que é ser cidadão.

\section{Por um artista-flâneur nas periferias}

O "príncipe dos ladrões", quando não viveu experiências sensíveis na periferia, ao chegar como estrangeiro, choca-se com o desafio aqui lançado. Para tentar sublinhar essa questão e ampliar o debate aqui proposto, para além do Robin Hood, outro personagem surge para elucidar a possibilidade real de construção desse artista-cidadão tão defendido nesse artigo. Trata-se do "Flâneur", revisitado do final do século XIX na Europa e que, a partir da obra de Charles Baudelaire, revela consigo uma potência simbólica de grande relevância para pensar a arte que busca esse diálogo com a cidade e o espaço público. Localizado no contexto do advento da modernidade, o flâneur é aquele que não se sente tranquilo no lugar em que está inserido, mas que, ao estar fora de casa, sente-se "em casa onde quer que esteja" (BAUDELAIRE, 2010, p. 29). Através da observação apaixonada dos espaços arquitetônicos, culturais e econômicos da cidade, num "espírito vagabundo, cheio de curiosidades malsãs e os nervos com um perpétuo desejo incompreensível" (RIO, 2008, p. 3), o flâneur é capaz de compreender a singularidade poética inscrita no cotidiano ao tempo que se relaciona de forma crítica, ampliada e implicada com o discurso que parte dessa observação.

Ao passo que as grandes cidades são modernizadas e capitalizadas em todas as suas relações de poder, marketing e comércio, as periferias demostram, mesmo sem querer ${ }^{8}$, um 


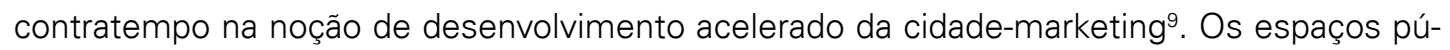
blicos das periferias ainda são tomados pelo sentimento de comunidade partilhada, onde os sujeitos transitam as ruas como donos de uma realidade da troca e da relação, noção tão difícil de ser percebida na cidade-marketing permeada de grandes condomínios e esquemas de segurança eletrônica. O desafio do artista contemporâneo, conforme mencionado outrora, é habitar esses espaços sensíveis sem capitanear ou colonizar experiências de resistência a um mundo cada vez mais monetizado e monitorado.

O flâneur ressurge como esse sujeito entregue a uma observação sensível do espaço que the cerca, inquieto com seu olhar crítico, ávido por compreender a imanência poética das arquiteturas, topografias e geografias da cidade, buscando "ver o mundo, estar no mundo e permanecer escondido no mundo, tais são alguns dos menores prazeres destes espíritos independentes, apaixonados, imparciais, que a linguagem dificilmente pode entender" (BAUDELAIRE, 2010, p. 29). É interessante perceber que Baudelaire pensou a sua obra no século XIX, tempo de expansão do capitalismo. Esse flâneur observava as ruas como esse sujeito intranquilo, que se relaciona com o passado e com a tradição em eterno devir do tempo presente e a visão de futuro, numa construção intempestiva de agora que se relaciona com as diversas forças que o entrecruzam, construindo um olhar multi-temporal sobre o espaço. Atualizando esse personagem (se é que ele um dia esteve localizado num tempo único), a flanerie, atitude do flâneur em percorrer os espaços públicos implica um desejo de compreensão das forças do tempo sobre o espaço e do espaço sobre o tempo, relacionando melancolia e progresso numa constante implosão crítica. O flâneur é um intranquilo e a flanerie, desse modo, suscita paradoxos. Ao chegar às periferias da cidade, o artista-flaneur ${ }^{10}$ percebe a incumbência de uma observação implicada que suscita vivência para a construção da experiência sensível, o que significa dizer que não basta chegar à periferia com os estereótipos marcados pelas imagens capitalísticas das cidades e acreditar que vai salvar uma população das forças hegemônicas ${ }^{10}$ do capitalismo. Assim como não basta, de outro modo, acreditar que se pode chegar à periferia totalmente esvaziado de experiências e construir um novo, partindo do zero da existência e da resistência. O flâneur será sempre um sujeito implicado, e mais, implicante: com o mundo que Ihe cerca, com os conflitos centro-periferia, com seu tempo-espaço, consigo mesmo e com seu mundo. O artista-flâneur, ao invés do furto do Robin Hood, traz soma e entrega uma antropofagia de si mesmo e do outro, o flâneur é por si só alteridade. 
A flanerie periférica pode desse modo, ser compreendida como um pontapé para uma arte que pretende dialogar com os tensionamentos culturais, estéticos e sociais das periferias de uma cidade. Através da observação dos espaços, é possível apropriar-se, mesmo que de forma momentânea, do espírito que lhe cerca, percebendo a sua "alma encantadora", a sua singularidade poética e a imanência do teatro a ser vivido nesse instante. Amir Haddad fala para seus atores que o teatro está no ar, nas partículas do ar que respiramos como pixels a serem baixados num download realizado pelo artista. Esse download só pode ser realizado a partir de uma sensibilidade extrema, da entrega ao acontecimento gravado na vida cotidiana, nos desenhos arquitetônicos de uma geografia resinificável, na intempestividade de um agora sempre novo e num sujeito-mundo que se percebe afetado e disparador de afeto do lugar que Ihe cerca. Paul Klee diz que

\footnotetext{
"para decolar da terra, exercemos um esforço por impulsos", que "nos elevamos sobre ela sob o império das forças centrífugas, que triunfam da gravidade". Acrescenta que o artista começa por olhar em volta dele, para todos os meios, a fim de apreender o sinal da criação no criado, da natureza naturante na natureza naturada; e depois, instalando-se "nos limites da terra", ele se interessa pelo microscópio, pelos cristais, pelas moléculas, pelos átomos e partículas, não pela conformidade científica, mas pelo movimento, nada mais que pelo movimento imanente. (DELEUZE, GUATARRI apud JACQUES, 2011, p. 145-146).
}

Pensar num teatro imanente, passível de download, não seria, contudo, negar a liberdade criativa do artista, limitando-o ao conjunto de regras já estabelecidas no mundo? Suscitar a arte da natureza do mundo, visto que tudo é arte, não seria limitar o campo de ação do artista, colocando-o apenas como programador de um estado poético já dado? A fala de Paul Klee atravessada pela compreensão desse artista-flâneur pode ser uma chave para desvendar esse paradoxo que diversos autores passaram anos debatendo enquanto paradigma na arte ${ }^{11}$. Compreender o sujeito enquanto cultura significa suscitar não somente a interferência do mundo na sua construção, mas, em paralelo, a sua intervenção inelutável no mundo que o cerca. O artista passa, então, a ser um organizador das moléculas e átomos imanentes já dadas no espaço para a construção do novo poético e singular, articulando um rizoma de forças que se operam no resultado do seu olhar sensível e da singularidade dos produtos sempre abertos que nascem dessa percepção. O artista-flâneur é sim o operador de um download do mundo poético que já está nas partículas espalhadas no ar, mas ele é, acima de tudo, aquele que é 
capaz de transformar e subverter, a partir da sua experiência, a ordem dessa constituição para a criação de rotas de fuga sempre em movimento, nunca estáticas. O flâneur é aquele sujeito que liberou o seu olhar à capacidade de se afetar com o novo espaço que lhe cerca, ao tempo que consegue articular essa experiência com o universo de intervenções sensíveis que ele é capaz de agenciar num exercício utópico, por isso mesmo experimental, da liberdade.

Como aponta Paola Berenstein Jacques no livro Estética da Ginga, Oiticica, chegando ao Morro da Mangueira, precisou se deslocar do seu espaço comum, realizar um encontro de afetos e experiências, implicar-se na construção da comunidade para daí perceber a potência estética do lugar e como ela lhe transformava. Oiticica foi um artista-flâneur da periferia, transportando para a sua experiência o outro que ele encontrou nessa troca, tornando-se também outro, sempre em devir: alteridade. É aqui que a noção de flanerie pode ser atualizada com a ideia de "Delírio Ambulatório", desenvolvida por Hélio no final dos anos 1970 após o retorno para o Rio de Janeiro e a partir das suas caminhadas pelas cidades, sintetizando a sua experiência "da descoberta da rua através do andar... do espaço urbano através do detalhe, do andar... do detalhe síntese do andar" (OITICICA apud JACQUES, 2011, p. 132). Ele buscava, caminhando, desmitificar a experiência no espaço público a partir de olhar estrangeiro, diferenciado, tentativa de fuga das forças hegemônicas que operam sobre o espaço observado e sobre o olhar, realizando, a partir do sensível, a descoberta do que está oculto pelas forças arrasadoras do discurso-marketing ${ }^{12}$. É essa percepção ambulatória que engendra, segundo ele, ações criativas, tendo em vista que ambulatoriar é "inventar 'coisas para fazer' durante a caminhada" (OITICICA, 2011, p. 177-178). Oiticica nos alertou da necessidade de desmitificar o próprio olhar, trazendo ao artista o desafio de uma percepção mais aguçada, ato que só se tornou possível quando ele descobriu a rua através do andar, nesse delírio ambulatório do deslocamento pelos territórios, quando ele não se nutre apenas "do que é perceptível na rua, mas também se apropria do simples saber dos dados inertes, que passam a ser então algo vivido, uma experiência" (BENJAMIN, 2009, p. 434-435).

É interessante perceber que a ideia de participação do espectador na obra de Oiticica de desenvolveu a partir da sua vivência na Mangueira, onde ele passa a defender que "o espectador não se torna somente participante (...), torna-se também parte da obra" (JACQUES, 2009 , p. 36). Esse deslocamento mudou consideravelmente a forma de produção artística de Hélio, que passa a se compreender como artista-cidadão propositor de práticas poéticas 
junto ao cidadão-artista. Foi a partir da sua flanerie, do seu contato com a periferia, com o samba carioca e com bases populares dos modos de se viver e estar no mundo que o artista pôde deslocar não somente sua produção artística, mas sua própria visão de mundo, cada vez menos separada da arte. É essa reivindicação de religação entre artista e mundo, arte e cidadão, experiência estética e vida, tão presente nas obras de Oiticica e do Tá na Rua, além de um grande número de outros artistas, que propicia uma reviravolta na arte contemporânea, suscitando modelos de coparticipação do cidadão-artista na construção poética das cidades, rumo à emancipação das relações e do sensível, na luta ainda utópica de fuga das influências capitalísticas tão presentes no atual mercado da arte e da economia da cultura vigentes.

Artigo recebido em julho de 2015 e aprovado em agosto de 2015.

\section{Notas}

1 A compreensão de um retorno às bases de contato com a rua insere as artes populares no curso do movimento histórico anterior ao advento das burguesias, onde os espaços públicos eram utilizados para as manifestações estéticas, período anterior à construção dos grandes teatros e espetáculos realizados de acordo com os interesses econômicos da classe dominante.

2 É Raymond Willians que lança-nos a compreensão de uma cultura comum (diferente de uma cultura em comum), traçada coletivamente, "refeita e redefinida pela prática de seus membros, e não aquela na qual valores criados pelos poucos são depois assumidos e vividos passivamente pelos muitos" (EAGLETON, 2011, p. 169).

3 Baudelaire, embora exerça o seu elogio à artificialidade, reivindica a noção de um "homem no mundo", ao invés de um artista Argumenta que é necessário entender a obra de Constantin Guys como a de um "homem do mundo inteiro, homem que compreende o mundo e as razões misteriosas e legítimas de todos os seus costumes" (BAUDELAIRE, 2010, p 25), ao passo que o artista é especialista, "homem preso à paleta tal como servo à gleba, (...) sua conversa, forçosamente limitada a um círculo muito estreito, depressa se torna insuportável ao homem do mundo, ao cidadão espiritual do universo" (BAUDELAIRE, 2010, p. 25-26).

4 Artista cearense Mestre em Linguagens Visuais pela UFRJ.

5 Beuys, artista visual e professor universitário, também foi um importante precursor das discussões aqui levantadas. É dele a célebre frase: "Cada homem é um artista". Contudo, diferente das noções de Oiticica, "Beuys mantinha a postura de artista-professor, ao passo que Oiticica se via mais como artista coautor que incita os espectadores à participação" (JACQUES, 2009, p. 150).

60 conceito de arte pública fala de uma arte em espaços públicos. A aplicação deste conceito às artes cênicas se expande quando o espectador passa a ser visto como coautor da experiência efêmera do teatro.

7 Guatarri e Rolnik (1986, p. 16) apresentam o termo 'capitalístico' defendendo que “a própria essência do lucro capitalista não se reduz ao campo da mais-valia econômica: ela está também na tomada de poder da subjetividade".

8 Destaco os movimentos que tem lutado para os direitos de cidadania das populações periféricas, reivindicando melhorias nas 
estruturas de saneamento, urbanização, além da mais recente discussão sobre a desmilitarização da polícia, movimento importante para o combate do extermínio das juventudes negras das periferias.

9 Pedro Celedón Bañados, doutor em história da arte contemporânea, aprofunda o conceito de cidade-marketing a partir de referencia a estudos econômicos e da compreensão de que os espaços pseudo-públicos são controlados por grandes instituições de poder que regem os significados de um grande cenário urbano controlado pelo marketing.

10 É relevante destacar a reivindicação do Movimento Esteticista Europeu do século XIX para o entrelaçamento entre arte e vida, suscitando os valores estéticos implícitos no cotidiano da aristocracia. Contudo, tal movimento reivindicava, em paralelo, a fuga do sentido social, moral e ético inscrito na arte e na sua relação com a conjuntura política de sua época, num sentimento blasé de não afetação, já que possuem "ao seu dispor e em larga medida, tempo e dinheiro, sem os quais a fantasia, reduzida ao estado de divagação passageira, não pode de modo algum traduzir-se em ação" (BAUDELAIRE, 2010, p. 64). O dandismo ao reivindicar a inutilidade da arte parte do desejo de contrariar o projeto massificador da sociedade, contudo deixa de levar em consideração os conflitos inseridos pelas camadas populares na sua relação com o trabalho e o operariado, inscrevendo na arte uma experiência elitista e sem relação com as contradições do capitalismo em fase de ascensão. O flâneur, mesmo inserido neste contexto, consegue dar uma dobra no esteticismo quando age na observação, implicação e construção simbólica e poética das cidades, tendo a flanerie como a imagemchave do seu universo. Mesmo ambientado nesse contexto, o que de certo já traz para o conceito "flâneur" o seu significado poético e artístico, faz-se relevante destacar o termo artista-flâneur para pensá-lo na contemporaneidade, onde o ífem presente nessa expressão reafirma o papel do artista inserido no seu tempo, ao passo que o distancia da noção unicamente estetizante presente no século XIX.

11 Villem Flusser faz um debate mais profundo dessa questão, apresentando, a partir da sua Filosofia da Caixa Preta, a reflexão de que o artista que trabalha com as imagens técnicas não passa de apertador de teclas, programador de um conjunto de virtualidades já dadas.

12 No caso de Fortaleza, realizar uma desmitificação sobre as periferias da cidade torna-se de grande relevância, em especial pela força dos programas televisivos que reforçam diariamente a noção do lugar violento e perigoso da cidade, contribuindo para a segregação e higienização dos espaços.

\section{Referências}

BAUDELAIRE, Charles. O pintor da vida moderna. São Paulo: Bira Câmara Editor, 2010.

BENJAMIN, Walter. Passagens. São Paulo: Imprensa Oficial, 2009.

EAGLETON, Terry. A ideia de cultura. São Paulo: Editora UNESP, 2011.

GUATTARI, F.; ROLNIK, S. Micropolítica: cartografias do desejo. Petrópolis: Vozes, 1986.

HADDAD, Amir. Espaço / / Espaço // / O teatro e a cidade, o ator e o cidadão. In: TURLE, Licko; TRINDADE, Jussara (orgs). Tá na rua: teatro sem arquitetura, dramaturgia sem literatura, ator sem papel. Rio de Janeiro: Instituto Tá Na Rua, 2008.

JACQUES, Paola Berenstein. Estética da ginga. A arquitetura das favelas através da obra de Hélio Oiticica. Rio de Janeiro, Casa da Palavra, 2011

MERLEAU-PONTY, Maurice. The visible and the invisible (Evanston: Northwestern University Press, 1992) 
OITICICA, Hélio. Mitos vadios. In: OITICICA FILHO, César (Org.). Hélio Oiticica. Museu é o mundo. Rio de Janeiro: Editora Azougue, 2011,

PEDROSA, Mário. Mundo, homem, arte em crise. São Paulo: Perspectiva, 1975.

RANCIĖRE, Jacques. O mestre ignorante: cinco lições sobre emancipação intelectual. Belo Horizonte: Autêntica, 2002.

RIO, João do. A alma encantadora das ruas. Organização de Raul Antelo. São Paulo: Companhia das Letras, 1997.

ROCHA, Enrico. O mundo é a obra. In: Jornal O Povo, de 01 de maio de 2014

Nem marginal nem herói. In: Jornal Diário do Nordeste, de 01 de maio de 2014. 